\title{
Evaluation of Dermoscopic Features in Facial Melanosis with Wood Lamp Examination
}

\author{
Bibush Amatya ${ }^{1}$
}

1 Nepal Medical College and Teaching Hospital, Kathmandu, Nepal

\begin{abstract}
Key words: facial melanosis, melasma, Wood lamp, dermoscopy
Citation: Amatya B. Evaluation of dermoscopic features in facial melanosis with Wood lamp examination. Dermatol Pract Concept. 2022;12(1):e2022030. DOI: https://doi.org/10.5826/dpc.1201a30
\end{abstract}

Accepted: July 25, 2021; Published: January 2022

Copyright: $\odot 2022$ Amatya. This is an open-access article distributed under the terms of the Creative Commons Attribution-NonCommercial License (BY-NC-4.0), https://creativecommons.org/licenses/by-nc/4.0/, which permits unrestricted noncommercial use, distribution, and reproduction in any medium, provided the original authors and source are credited.

Funding: This study was supported by the International Dermoscopy Society Research Seed Grant, 2019.

Competing interests: None.

Authorship: The author takes responsibility for this publication.

Corresponding author: Bibush Amatya, MBBS, MPH, MD Dermatology, Venereology and Leprology, Nepal Medical College and Teaching Hospital, Kathmandu, Nepal. Email: bibush.amatya@nmcth.edu

ABSTRACT Introduction: Facial melanosis is one of the most common reasons for which patients refer to a der-
matologist in Nepal.
Objectives: The objective of this study was to evaluate the dermoscopic findings of common facial
melanoses and correlate them with findings from Wood lamp examination.
Methods: This was a cross-sectional study conducted at the Department of Dermatology and Vene-
reology, Nepal Medical College and Teaching Hospital. We recruited a total of 204 patients from July
2020 to March 2021 . The most common diagnosis was melasma ( 37 patients) followed by melasma
with steroid-induced rosacea-like dermatitis ( 29 patients). After collecting clinical and demographic
data, patients underwent Wood lamp and dermoscopic examination.
Results: Dermoscopy of ashy dermatosis and nevus of Ota revealed blue-gray pigmentation forming
a curvilinear pattern; café-au-lait macule and nevus spilus revealed a light brown reticular pattern
with follicular sparing; and a reticular and hem-like pattern of pigmentation was observed in clo-
fazimine-induced pigmentation, peribuccal pigmentation of Brocq and periorbital pigmentation. The
degree of agreement between Wood lamp and dermoscopic findings was found to be statistically sig-
nificant in melasma $(\kappa=0.701, \mathrm{P}=0.0001$ ) and melasma with steroid-induced rosacea-like dermatitis
( $\kappa=0.628, \mathrm{P}=0.0001)$. While the agreement between the two techniques was $100 \%$ for epidermal
types, it decreased to $44.8 \%$ for dermal melasma and $61.5 \%$ for dermal melasma with steroid-induced
rosacea-like dermatitis.

Conclusions: Dermoscopy is useful in assessing facial melanoses. It may be supplemented with Wood lamp examination to increase diagnostic accuracy. 


\section{Introduction}

Facial melanoses are characterized by abnormal pigmentation of the face. These disorders include, but are not limited to, ashy dermatosis, discoid lupus erythematosus, ephelides, melasma, melasma with steroid-induced rosacea-like dermatitis, peribuccal pigmentation of Brocq, periorbital hyperpigmentation, postinflammatory hyperpigmentation, and solar lentigo. Also included are various types of nevi, such as Becker nevus, blue nevus, compound nevus, Hori nevus, intradermal nevus, junctional nevus, nevus of Ota, nevus spilus, and verrucous epidermal nevus [1]. Facial melanoses may also present as a result of ingestion of certain drugs like amiodarone, antimalarials, antipsychotics, chloramphenicol, clofazimine, pirfenidone and tetracycline [2].

The diagnosis and differentiation of these conditions are based on history and clinical examination supplemented in some cases by Wood lamp and histopathological evaluation [3]. Dermoscopy is a noninvasive, in vivo technique that allows visualization of the subsurface structures of skin that are normally not visible to the naked eye. Wood lamp examination is another non-invasive technique that helps in the diagnosis of pigmentary disorders. It uses a specific wavelength light source to distinguish depth of pigmentation depending on different degrees of auto-fluorescence [4]. There are very few studies that have evaluated dermoscopic and Wood lamp findings for the diagnosis and classification of all facial melanoses [5]; some studies have only focused on melasma [6-8]. We therefore aimed to evaluate the dermoscopic findings of common facial melanoses and correlate them with findings from Wood lamp examination.

\section{Methods}

This was a cross-sectional study conducted at the Department of Dermatology and Venereology, Nepal Medical College and Teaching Hospital (NMCTH), Kathmandu, Nepal. The study subjects included all patients with a facial melanosis who visited the dermatology outpatient department from July 1, 2020, to March 31, 2021. All participants provided written informed consent for participation. The Institutional Review Committee of NMCTH granted approval to conduct the study (reference number 040-076/076).

At the time of enrolment, the investigator filled a form to obtain information on patient age, sex, diagnosis, and Fitzpatrick skin type. The diagnosis was based on clinical examination performed by a dermatologist. Clinical photographs were obtained using iPhone 6s plus (Apple® Inc). A dermatologist examined the participants with a Wood lamp (Derma India) to assess the depth of pigmentation, and the investigator performed dermoscopic examination (DermLite DL4, 3 GenInc).
The data were uploaded onto a secure password-protected database using Microsoft Excel. Data analysis was performed with the Statistical Package for Social Sciences (SPSS) version 16 (SPSS Inc). Descriptive statistics were utilized to compute the mean and standard deviation (SD) of age and frequency of facial melanoses. Wood lamp and dermoscopic findings were analyzed using Cohen's kappa coefficient, and correlation was established. A P value $<0.05$ was considered statistically significant.

\section{Results}

A total of 204 patients provided informed consent to participate in the study. Most participants were female (146, $71.6 \%$ ). The mean (SD) age of the participants was $34.04 \pm$ 13.17 years with a range $13-86$ years. The highest percentage of participants $(72.5 \%)$ belonged to the age group 21-40 years. In our sample, $24 \%$ had Fitzpatrick skin type III, $65.7 \%$ had skin type IV, and $10.3 \%$ had skin type V.

The most common diagnosis was melasma (47 patients, $23 \%$ ) followed by melasma with steroid-induced rosacea-like dermatitis (29 patients, $14.2 \%$ ). The rarest observed conditions were ashy dermatosis (1 patient), lentigo simplex (1 patient), nevus of Ota ( 1 patient), and nevus spilus (1 patient). Female predominance was observed in melasma (4.2:1), melasma with steroid-induced rosacea-like dermatitis (13.5:1), and ephelides (100:0). The two patients with nevus of Ota and nevus spilus were males (Table 1 ).

Wood lamp examination was performed in all patients. Accentuation of pigmentation was observed in all cases of acne-induced postinflammatory hyperpigmentation, blue nevus, café-au-lait macule, compound nevus, dermatosis papulosa nigra, discoid lupus erythematosus, ephelides, Hori nevus, junctional nevus, lentigo simplex, nevus of Ota, nevus spilus, postinflammatory hyperpigmentation, seborrhoeic keratosis, solar lentigo and verrucous epidermal nevus. Such accentuation was not observed in patients with ashy dermatosis and peribuccal pigmentation of Brocq. Epidermal as well as dermal pigmentation were observed in melasma, melasma with steroid-induced rosacea-like dermatitis, dermal nevus, periorbital hyperpigmentation and clofazimine induced pigmentation.

The dermoscopic findings of common facial melanoses are given in Table 2. Acne-induced postinflammatory hyperpigmentation was characterized by reddish brown homogenous pigmentation on a reddish background (Figure 1A), and postinflammatory hyperpigmentation secondary to trauma revealed a dark brown reticular or homogenous pattern with dark brown dots (Figure 1B). Dermoscopy of ashy dermatosis and nevus of Ota revealed blue-gray pigmentation forming a curvilinear pattern (Figure 2). Dark brown reticular pattern with follicular sparing was observed in both café-au-lait macule 
Table 1. Pattern and Gender Distribution of Facial Melanoses

\begin{tabular}{|l|c|c|c|}
\hline \multicolumn{1}{|c|}{ Diagnosis } & Males, $\mathbf{n}(\%)$ & Females, $\mathbf{n}(\%)$ & Number, $\mathbf{n}(\%)$ \\
\hline Melasma & $9(19.2)$ & $38(80.9)$ & $47(23)$ \\
\hline Melasma with steroid-induced rosacea-like dermatitis & $2(6.9)$ & $27(93.1)$ & $29(14.2)$ \\
\hline Compound nevus & $10(37)$ & $17(63)$ & $27(13.2)$ \\
\hline Ephelides & 0 & $16(100)$ & $16(7.8)$ \\
\hline Acne-induced postinflammatory hyperpigmentation & $6(46.2)$ & $7(53.8)$ & $13(6.4)$ \\
\hline Blue nevus & $5(41.7)$ & $7(58.3)$ & $12(5.9)$ \\
\hline Seborrhoeic keratosis & $6(54.5)$ & $5(45.5)$ & $11(5.4)$ \\
\hline Junctional nevus & $4(44.4)$ & $5(55.6)$ & $9(4.4)$ \\
\hline Periorbital hyperpigmentation & $4(57.1)$ & $3(42.9)$ & $7(3.4)$ \\
\hline Solar lentigo & $2(40)$ & $3(60)$ & $5(2.5)$ \\
\hline Dermatosis papulosa nigra & 0 & $4(100)$ & $4(2)$ \\
\hline Postinflammatory hyperpigmentation & $2(50)$ & $2(50)$ & $4(2)$ \\
\hline Clofazimine-induced pigmentation & $2(66.7)$ & $1(33.3)$ & $3(1.5)$ \\
\hline Discoid lupus erythematosus & $2(66.7)$ & $1(33.3 \%)$ & $3(1.5)$ \\
\hline Café-au-lait macule & $1(50)$ & $1(50)$ & $2(1)$ \\
\hline Dermal nevus & $1(50)$ & $1(50)$ & $2(1)$ \\
\hline Hori nevus & 0 & $2(100)$ & $2(1)$ \\
\hline Peribuccal pigmentation of Brocq & 0 & $2(100)$ & $2(1)$ \\
\hline Verrucous epidermal nevus & 0 & $2(100)$ & $2(1)$ \\
\hline Ashy dermatosis & 0 & $1(100)$ & $1(0.5)$ \\
\hline Lentigo simplex & 0 & $1(100)$ & $1(0.5)$ \\
\hline Nevus of Ota & $1(100)$ & 0 & $1(0.5)$ \\
\hline Nevus spilus & $1(100)$ & 0 & $1(0.5)$ \\
\hline Total & $58(28.4)$ & $146(71.6)$ & 204 \\
\hline
\end{tabular}

Table 2. Dermoscopic Features of Facial Melanoses

\begin{tabular}{|l|l|c|}
\multicolumn{1}{|c|}{ Diagnosis } & \multicolumn{1}{|c|}{ Dermoscopic Features } & Percentage \\
\hline $\begin{array}{l}\text { Acne-induced } \\
\text { postinflammatory } \\
\text { hyperpigmentation }\end{array}$ & $\begin{array}{l}\text { Brown structureless areas } \\
\text { Brown reticular pattern }\end{array}$ & $78.6 \%$ \\
\hline Ashy dermatosis & Blue gray pigmentation forming a curvilinear pattern & $64.3 \%$ \\
\hline Blue nevus & Blue gray homogenous pattern & $100 \%$ \\
\hline Café-au-lait macule & Light brown reticular pattern & $100 \%$ \\
\hline Clofazimine induced & Blue gray dots & $100 \%$ \\
pigmentation & Coppery red background & $50 \%$ \\
\hline Compound nevus & Brown homogenous pattern & $100 \%$ \\
& Hem-like pattern & $66.7 \%$ \\
\hline Dermal nevus & Diffuse black homogenous pattern & $66.7 \%$ \\
\hline Dermatosis papulosa nigra & Dark brown globular pattern & $51.9 \%$ \\
\hline Discoid lupus & Cobblestone pattern, Tan structureless area & $18.5 \%$ \\
\hline erythematosus & Follicular keratotic plugs, dark brown pigmentation & $100 \%$ \\
\hline Ephelides & Perifollicular halo, White structureless areas & $100 \%$ \\
\hline Hori nevus & Telangiectatic vessels & $100 \%$ \\
\hline & Brown reticular pattern with moth-eaten border & $100 \%$ \\
\hline & Dark brown dots & $100 \%$ \\
\hline
\end{tabular}


Table 2. Dermoscopic Features of Facial Melanoses. (continued)

\begin{tabular}{|l|l|c|}
\hline \multicolumn{1}{|c|}{ Diagnosis } & \multicolumn{1}{|c|}{ Dermoscopic Features } & Percentage \\
\hline Junctional nevus & Dark brown reticular pattern & $55.6 \%$ \\
& Light brown reticular pattern, Interspersed brown dots & $33.3 \%$ \\
\hline Lentigo simplex & Brown reticular pattern with moth-eaten border & $100 \%$ \\
\hline Melasma & Arciform structures & $85.1 \%$ \\
& Telangiectasia & $83 \%$ \\
& Dark brown to bluish gray reticular pattern & $61.7 \%$ \\
& Light brown reticular pattern & $44.3 \%$ \\
\hline Melasma with steroid- & Telangiectasias & $100 \%$ \\
induced rosacea-like & Arciform structures & $93.1 \%$ \\
dermatitis & Dark brown to bluish gray reticular pattern & $79.3 \%$ \\
& Light brown reticular pattern & $55.2 \%$ \\
& Dilated tortuous branched vessels giving a polygonal appearance & $48.3 \%$ \\
& Terminal hair & $17.2 \%$ \\
\hline Nevus of Ota & Blue gray pigmentation forming a curvilinear pattern & $100 \%$ \\
\hline Nevus spilus & Light brown reticular pattern & $100 \%$ \\
\hline Peribuccal pigmentation of & Dark brown reticular pattern & $100 \%$ \\
& Dark brown hem-like pattern & $50 \%$ \\
\hline Brocq & Dark brown reticular pattern & $100 \%$ \\
heriorbital & Dark brown hem-like pattern & $100 \%$ \\
& Cobblestone pattern & $57.1 \%$ \\
\hline Postinflammatory & Dark brown reticular pattern & $50 \%$ \\
hyperpigmentation & Moth-eaten borders & $50 \%$ \\
& Dark brown homogenous pattern & $25 \%$ \\
\hline Seborrheic keratosis & Dark brown peripheral reticular pattern with central hypopigmentation & $25 \%$ \\
\hline Verrucous epidermal nevus & Milia-like cysts & $63.6 \%$ \\
& Fissures and ridges & $54.5 \%$ \\
& Comedo-like openings & $36.4 \%$ \\
& Fingerprint-like structures & $27.3 \%$ \\
\hline Solar lentigo & Brown reticular pattern, Fingerprint-like structures & $80 \%$ \\
& Moth-eaten border & $80 \%$ \\
& Brown structureless homogenous pigmentation & $80 \%$ \\
& Expochromic areata & $80 \%$ \\
\hline & & $50 \%$ \\
& Exophytic structures & $50 \%$ \\
\hline
\end{tabular}
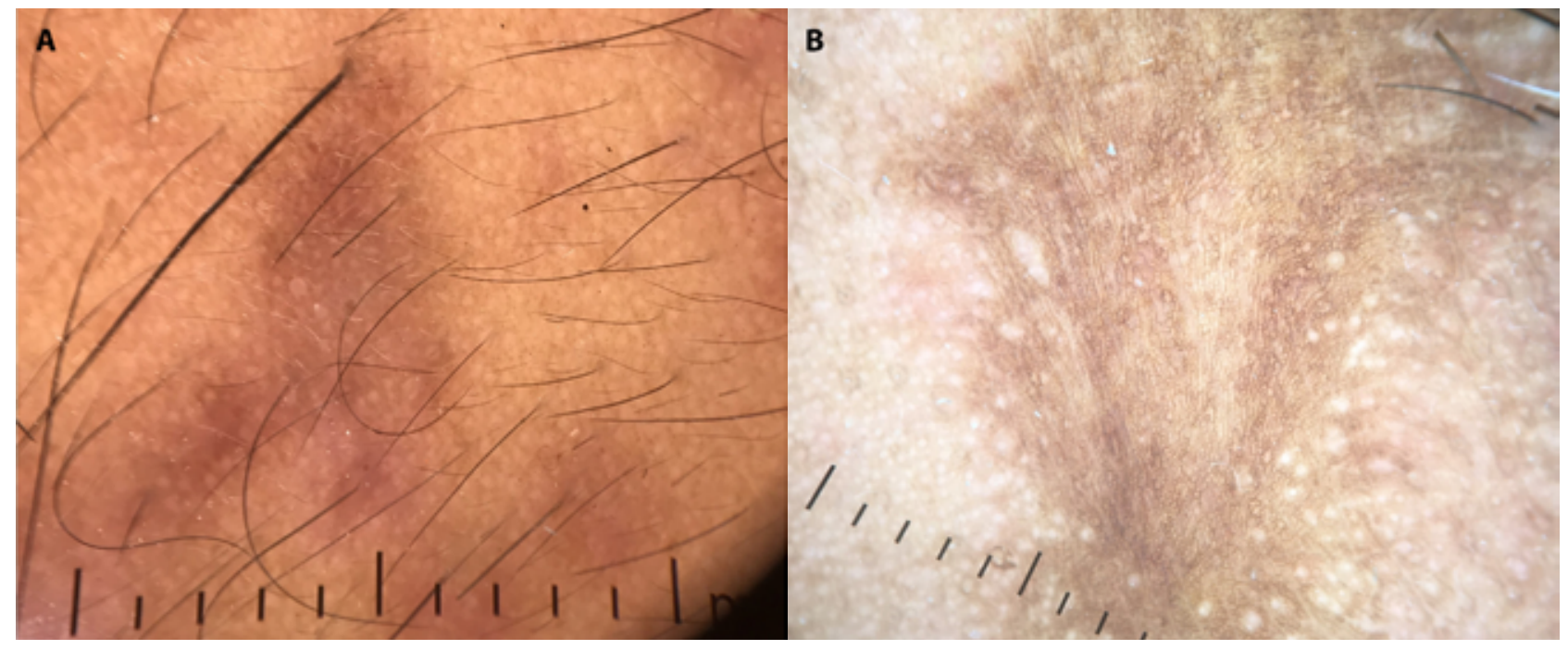

Figure 1. Dermoscopic image. (A) acne-induced post inflammatory hyperpigmentation showing homogenous dark brown pattern on a reddish background. (B) trauma-induced postinflammatory hyperpigmentation showing reticular dark brown pattern with dark brown dots. 


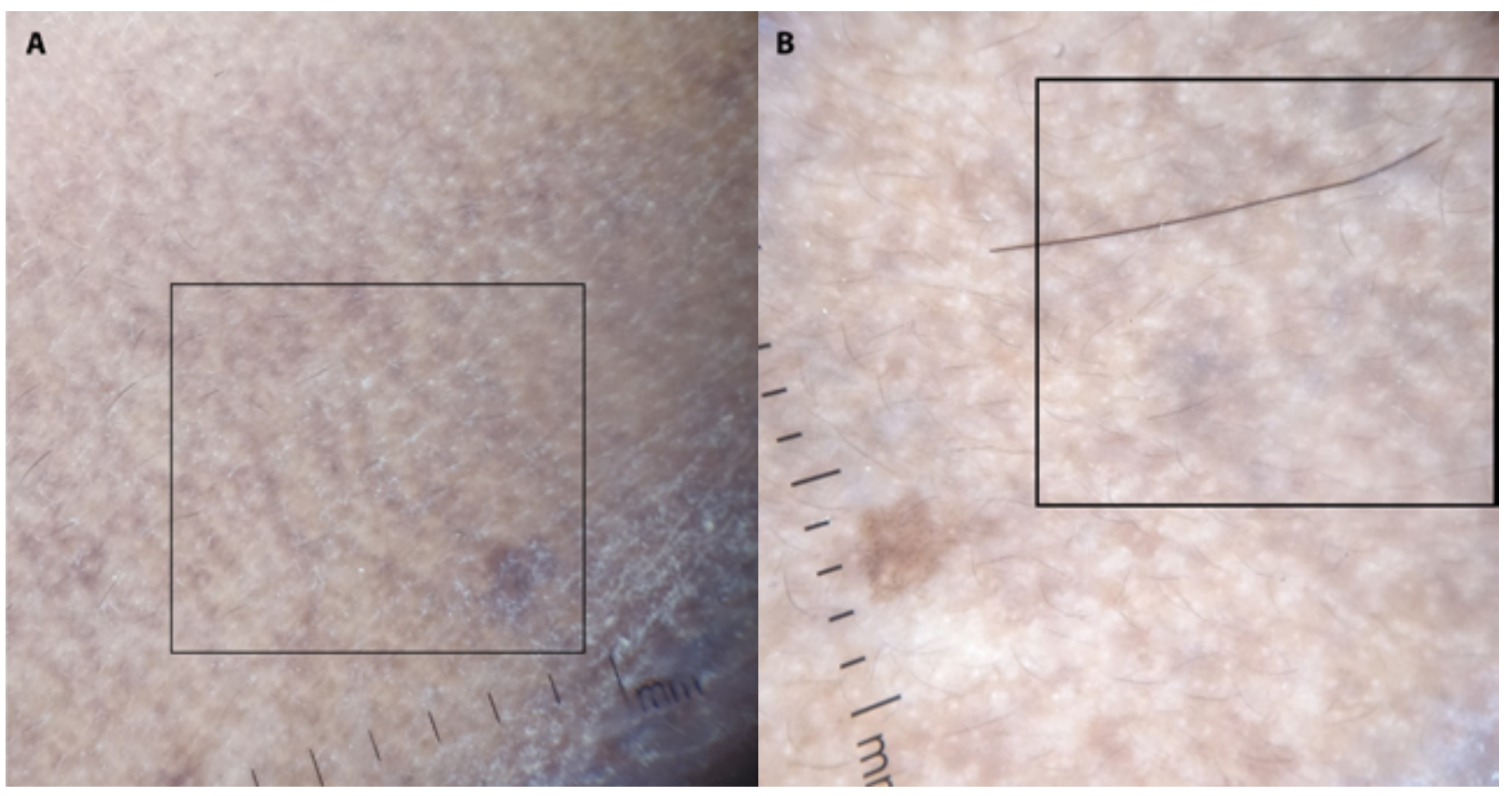

Figure 2. Dermoscopic image revealing blue gray pigmentation forming a curvilinear pattern (square). (A) ashy dermatosis. (B) nevus of Ota.

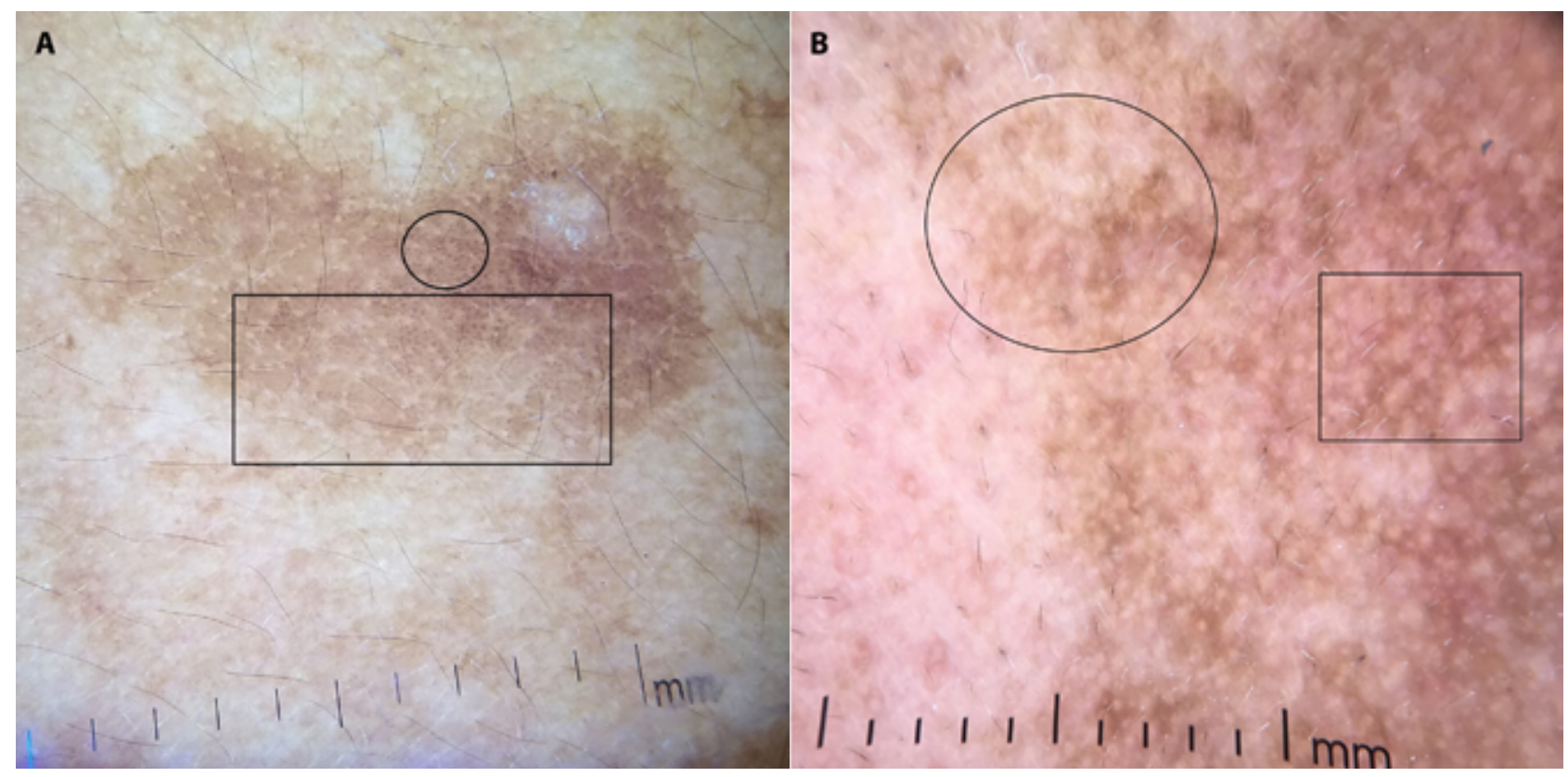

Figure 3. Dermoscopic image. (A) café-au-lait macule displaying a dark brown reticular pattern (rectangle) with dark brown dots (circle). (B) nevus spilus showing a reticular pattern (rectangle) with follicular sparing and perifollicular accentuation (circle).

and nevus spilus. In addition to the reticular pattern, the caféau-lait macule displayed dark brown dots and perifollicular accentuation was observed in nevus spilus (Figure 3).

Clofazimine-induced pigmentation, peribuccal pigmentation of Brocq, and periorbital pigmentation revealed a reticular and hem-like pattern of pigmentation on dermoscopy (Figure 4). The background was coppery red in clofazimine-induced pigmentation but not in the other two conditions (Figure 4). Hori nevus showed a speckled bluish brown pattern of pigmentation (Figure 5), and verrucous epidermal nevus revealed large brown circles with a hyperchromic brown edge surrounding a hypochromic area.

Melasma and melasma with steroid-induced rosacea-like dermatitis were classified into epidermal, dermal, and mixed types based on dermoscopic findings. The epidermal type was characterized by the presence of scattered islands of a light brown reticular network and the dermal type by dark brown to bluish gray irregular pigment network and arciform structures. The mixed type had presence of epidermal and dermal features (Figure 6$)$.There were $8(17.0 \%)$ epidermal, 


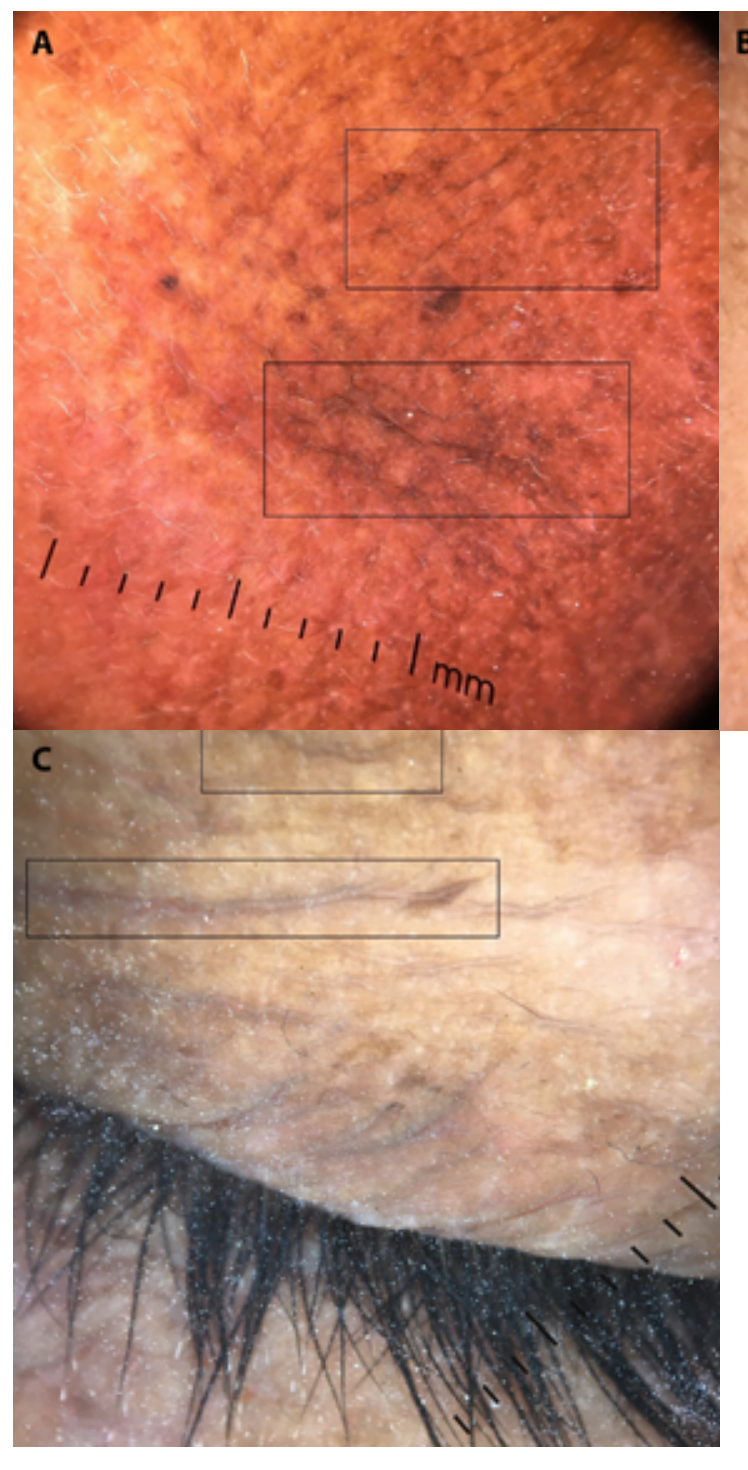

B

Figure 4. Dermoscopic picture showing dark brown hem-like pigment pattern (rectangle). (A) clofazimine-induced pigmentation on a coppery background. (B) peribuccal pigmentation of Brocq. (C) periorbital hyperpigmentation.

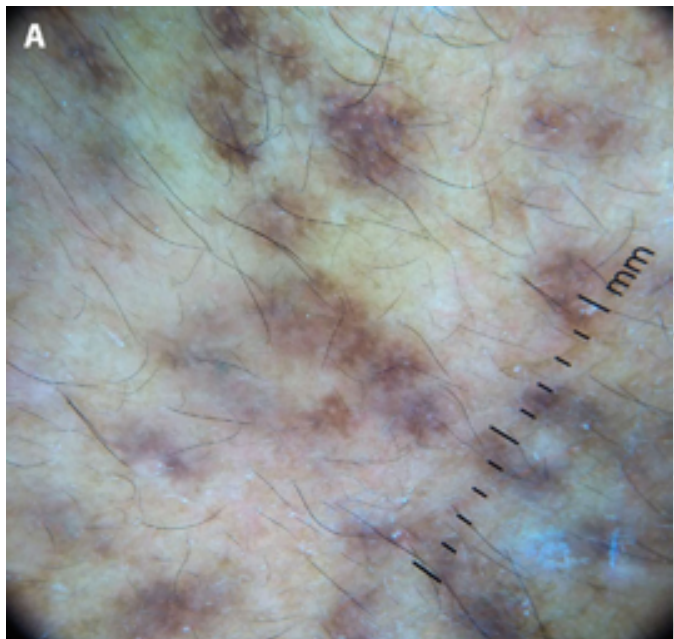

B

Figure 5. Dermoscopic image. (A) Hori nevus showing speckled bluish brown pigmentation. (B) verrucous epidermal nevus showing large brown circles with hyperchromic brown edge surrounding a hypochromic area (rectangle). 


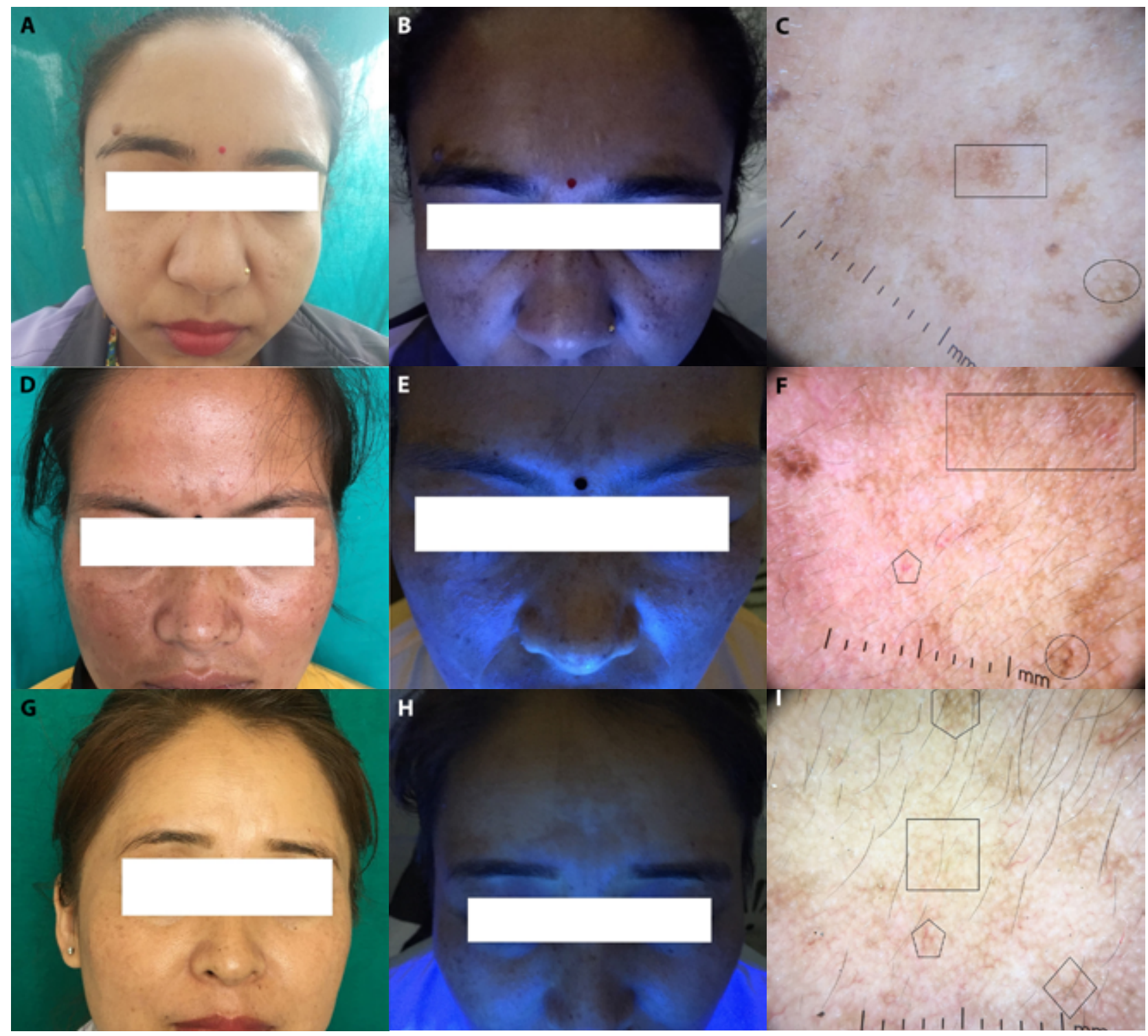

Figure 6. Clinical, Wood lamp examination, and dermoscopic images in epidermal, dermal, and mixed melasma. (A) epidermal melasma showing faint hyperpigmented macules in bilateral malar region showing accentuation. (B) on Wood lamp examination. (C) light brown reticular pattern (rectangle) and brown dots (circle) on dermoscopy.(D) Dermal melasma with dark brown hyperpigmented macules on the forehead. (E) malar region showing masking of pigmentation on Wood lamp examination. (F) dark brown irregular pigment network (rectangle), arciform structures (circle) and telangiectasia (pentagon) on dermoscopy. (G) Mixed melasma displaying light brown hyperpigmented macules on periorbital and forehead regions displaying accentuation on forehead. (H) masking on malar region on Wood lamp examination. (I) Dermoscopy shows light brown (rectangle) and dark brown (hexagon) pigment networks, arciform structures (diamond), and telangiectasia (pentagon).

Table 3. Correlation Between Wood lamp and Dermoscopic Findings in Melasma and Melasma with Steroid-Induced Rosacea-Like Dermatitis

\begin{tabular}{|c|c|c|c|c|c|c|}
\hline \multirow[b]{3}{*}{ Wood's lamp } & \multicolumn{4}{|c|}{ Melasma } & \multirow{3}{*}{$X^{2}$-value } & \multirow{3}{*}{$P$ value } \\
\hline & \multicolumn{4}{|c|}{ Dermoscopy } & & \\
\hline & Epidermal & Dermal & Mixed & Total & & \\
\hline Epidermal & $8(17 \%)$ & $0(0 \%)$ & $1(2.1 \%)$ & $9(19.1 \%)$ & 60.08 & 0.000 \\
\hline Dermal & $0(0 \%)$ & $13(27.7 \%)$ & $0(0 \%)$ & $13(27.7 \%)$ & & \\
\hline Mixed & $0(0 \%)$ & $8(17 \%)$ & $17(36.2 \%)$ & $25(53.2 \%)$ & & \\
\hline Total & $8(17 \%)$ & $21(44.7 \%)$ & $18(38.3 \%)$ & & & \\
\hline
\end{tabular}

(continues) 
Table 3. Correlation Between Wood lamp and Dermoscopic Findings in Melasma and Melasma with Steroid-Induced Rosacea-Like Dermatitis (continued)

\begin{tabular}{|c|c|c|c|c|c|c|}
\hline \multirow[b]{3}{*}{ Wood's lamp } & \multicolumn{4}{|c|}{ Melasma With Steroid-Induced Rosacea-Like Dermatitis } & \multirow{3}{*}{$X^{2}$ value } & \multirow{3}{*}{$P$ value } \\
\hline & \multicolumn{4}{|c|}{ Dermoscopy } & & \\
\hline & Epidermal & Dermal & Mixed & Total & & \\
\hline Epidermal & $6(20.7 \%)$ & $0(0 \%)$ & $0(0 \%)$ & $6(20.7 \%)$ & 34.00 & 0.000 \\
\hline Dermal & $0(0 \%)$ & $8(27.6 \%)$ & $2(6.9 \%)$ & $10(34.5 \%)$ & & \\
\hline Mixed & $0(0 \%)$ & $5(17.2 \%)$ & $8(27.6 \%)$ & $13(44.8 \%)$ & & \\
\hline Total & $6(20.7 \%)$ & $13(44.8 \%)$ & $10(34.5 \%)$ & & & \\
\hline \multicolumn{7}{|c|}{ Kappa statistics $=0.628, \mathrm{P}=0.0001$ (significant) } \\
\hline
\end{tabular}

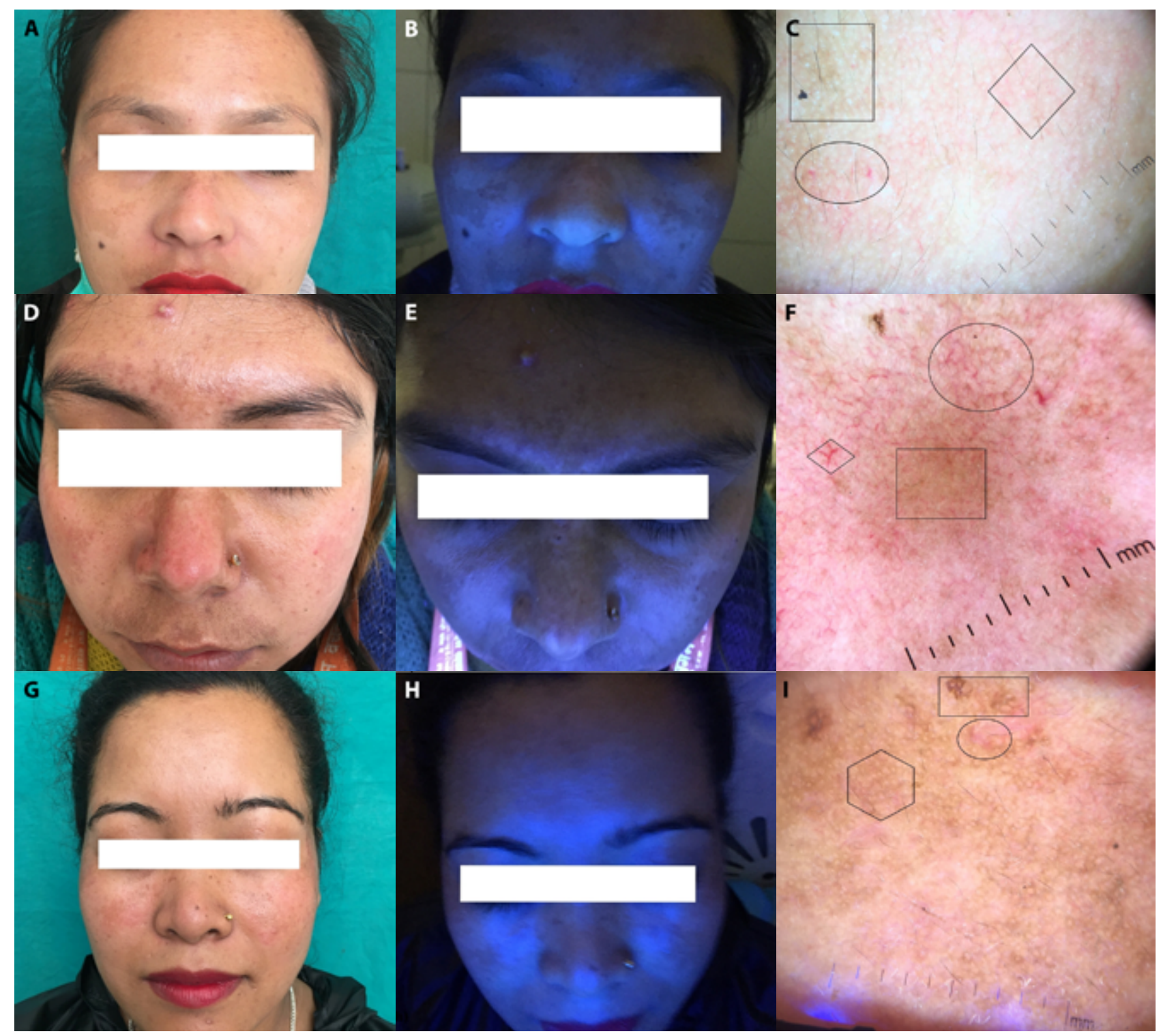

Figure 7. Clinical, Wood lamp examination and dermoscopic images in epidermal, dermal, and mixed melasma with steroid-induced rosacea-like dermatitis. (A) Epidermal melasma with steroid-induced rosacea-like dermatitis showing faint hyperpigmented macules in bilateral malar region. (B) accentuation on Wood lamp examination. (C) light brown reticular pattern (rectangle), dilated tortuous vessels (oval) forming a polygonal pattern (diamond) on dermoscopy. (D) Dermal melasma with steroid-induced rosacea-like dermatitis with dark brown hyperpigmented macules on forehead and malar region and erythema on bridge of nose. (E) masking of pigmentation on Wood lamp examination. (F) dark brown homogenous pigmentation (rectangle), dilated tortuous vessels (telangiectasia) forming a polygonal pattern (oval) on dermoscopy. (G) Mixed melasma displaying light brown hyperpigmented macules on malar region with faint erythema displaying accentuation on malar. (H) masking on the forehead region on Wood lamp examination. (I) Dermoscopy shows light brown (hexagon) and dark brown (rectangle) pigment network with red structureless areas (oval). 
$21(44.7 \%)$ dermal and $18(38.3 \%)$ mixed types of melasma. A similar pattern was observed in melasma with steroid-induced rosacea-like dermatitis: epidermal $(6,20.7 \%)$, dermal $(13,44.8 \%)$, mixed $(10,34.5 \%)$.

The degree of agreement between Wood lamp and dermoscopic findings was found to be substantial as analyzed by kappa statistics (Table 3). Of the 8 lesions considered as epidermal type by dermoscopy, the examination agreement under Wood lamp was $100 \%$. Of the 21 considered dermal by dermoscopy, the agreement with Wood lamp was only $44.8 \%$. And of the 18 considered mixed by dermoscopy, the agreement was $94.4 \%$ with Wood lamp examination.

Regarding melasma with steroid-induced rosacea-like dermatitis, 6 cases were classified as epidermal, 13 as dermal and 10 as mixed type. The agreement with Wood lamp examination was $100 \%$ for epidermal, $61.5 \%$ for dermal and $80.0 \%$ for mixed type. In addition, dermoscopy revealed follicular sparing with perifollicular accentuation (96.6\%), arcuate structures $(93.1 \%)$, dilated tortuous branched vessels giving a polygonal appearance $(44.8 \%)$ and terminal hairs $(10.3 \%)$ (Figure 7$)$.

Although the two cases of dermal nevus showed different patterns of autofluorescence on Wood lamp examination, there were no differences detected in dermoscopic examination. The three cases of dermal periorbital hyperpigmentation revealed dark brown reticular and hem-like pattern on dermoscopy while the epidermal cases showed cobblestone pattern in addition to the above features. Dark brown blotches, hem-like pattern on a coppery red background were observed in epidermal clofazimine-induced pigmentation while blotches were not seen in dermal clofazimine-induced pigmentation.

\section{Conclusions}

In our study, melasma was the most frequent diagnosis followed by melasma with steroid-induced rosacea-like dermatitis. Epidermal melasma was characterized by light brown reticular network, dermal by dark brown to bluish gray irregular pigment network and arciform structures and mixed by features of both epidermal and dermal types. Nanjundaswamy et al [9] also observed scattered islands of brown reticular network in epidermal melasma. Dermal melasma showed uniform skin involvement with dark brown to gray hyperpigmented irregular pigment network. Yalamanchili et al [10] also found light or dark brown, diffuse or patchy reticular pigmentation in $95 \%$ of patients with melasma.

Few studies have compared Wood lamp and dermoscopic findings in melasma. Tamler et al [6], in their study done in Brazil, found $44 \%$ agreement in epidermal melasma, 57\% in dermal melasma and $51 \%$ in mixed melasma. The degree of concordance was considered weak $(\mathrm{k}<0.2)$. Two stud- ies done in India found a substantial degree of agreement between Wood's lamp and dermoscopic findings in melasma. Dharni et al [7] found correlation between the two techniques in $56.25 \%$ of patients and the degree of agreement was statistically significant $(\mathrm{k}=0.813, \mathrm{P}=0.0001)$. Manjunath et al [8] also found a good degree of correlation $(\mathrm{k}=0.833, \mathrm{P}=$ 0.0001). In our study too, the degree of agreement was significant $(\mathrm{k}=0.701, \mathrm{P}=0.000)$. However, while the degree of agreement was $100 \%$ for epidermal type, it was only $44.8 \%$ for dermal melasma. The discrepancies could be attributed to better visualization of arciform structures and dark brown to bluish gray irregular pigment network in dermal melasma with dermoscopy.

In our setting, melasma with steroid-induced rosacea-like dermatitis is frequently encountered [3]. The main dermoscopic features identified were light to dark brown reticular pigment network, arcuate structures, dilated tortuous branched vessels giving a polygonal appearance and terminal hairs. Jakhar et al [11] in their case report on topical steroid dependent/damaged face discovered dilated tortuous branched vessels interconnecting with each other to form a polygonal pattern on dermoscopy. In addition, white structureless areas, yellowish areas and coarse terminal hairs were also visible [11]. According to them, white structureless areas correspond to dermal atrophy. We did not encounter white structureless areas in our study indicating that this could be an incidental finding. We also found correlation between Wood lamp and dermoscopic classification of melasma with steroid-induced rosacea-like dermatitis $(\mathrm{k}=0.628, \mathrm{P}=$ $0.0001)$, which has not yet been reported in the literature. Here again, while agreement was $100 \%$ in epidermal type, it decreased to $61.5 \%$ for dermal and $80 \%$ for mixed type. Thus, while Wood lamp examination may help to differentiate epidermal melasma from other types of conditions, it may not be so accurate for dermal or mixed melasma with steroid-induced rosacea-like dermatitis.

In this study, we had one patient with ashy dermatosis and one with nevus of Ota. The dermoscopic findings in both the cases were similar; blue gray pigmentation forming a curvilinear pattern. Gray dots and globules having an irregular linear arrangement in ashy dermatosis has also been reported by Elmas et al [12]. This arrangement has been named as broken lines and semi-arcuate structures appearing as Chinese letters by Vinay et al [13]. Blue gray pigmentation forming a curvilinear pattern on dermoscopic examination of nevus of Ota has not yet been described in the literature. In the study done by Elmas et al [14], the most common dermoscopic findings of nevus of Ota were brown and gray structureless areas having a patchy distribution. They also observed white clods in a "four dots clod" arrangement. El-Kadiri et al [15] observed blue grayish structureless areas with iridescent reflections and white rosettes in their case report on nevus of Ota. A 
curvilinear pattern could be discerned in the dermoscopic image in their case report, although it was not mentioned by the authors. Whether a curvilinear pattern is a characteristic feature of nevus of Ota remains to be explored.

Dark brown blotches, hem-like pattern of pigmentation on a coppery red background were observed on dermoscopic examination of patients with clofazimine-induced pigmentation. We identified only one study that had evaluated dermoscopic findings in clofazimine-induced pigmentation. Chopra et al [16] described honeycomb pattern with yellow to white globules interspersed along a dark to skin-colored background. To best of our knowledge, this is the first study identifying hem-like pattern of pigmentation in clofazimine-induced pigmentation.

We had seven cases of periorbital hyperpigmentation out of which four displayed accentuation of pigmentation on Wood lamp examination. All cases showed dark brown reticular and hem-like pigmentation on dermoscopic examination. The epidermal cases showed a cobblestone pattern in addition to the above features. Jage et al [17] evaluated the dermoscopic findings in 50 patients with periorbital hyperpigmentation in 2018 . The most common findings were blotches, exaggerated pigment network, coarse speckled, fine speckled and globules. Skin changes included atrophy and exaggerated skin markings. We believe the hem-like pigmentation (increased pigmentation along the skin folds) seen on dermoscopy corresponds to exaggerated skin markings. The exaggerated skin markings imply an atopic diathesis, post-steroid abuse or constitutional type of periorbital hyperpigmentation [17].

There were some notable limitations in the study. As it was a cross-sectional study, we could not obtain longitudinal data. This was especially true for discoid lupus erythematosus and ephelides, which have waxing and waning courses. Our hospital-based study also may be not??? representative of the general population.

Another limitation of our study is the relatively small sample size and the lack of histopathological correlation with dermoscopic examination. As this study took place during the peak of the COVID-19 epidemic in Nepal, this affected the sample size. Furthermore, most patients chose not to undergo an invasive procedure like biopsy for histopathological confirmation. We recommend future studies exploring correlation between dermoscopic and histopathological findings in all facial melanoses as dermoscopic information provided to pathologist can improve diagnostic accuracy.

The most frequent diagnoses in our study were melasma, melasma with steroid-induced rosacea-like dermatitis and various types of naevi. Dermoscopy of ashy dermatosis and nevus of Ota revealed blue gray pigmentation forming a curvilinear pattern. Café-au-lait macule and nevus spilus revealed light brown reticular pattern with follicular sparing on der- moscopy. Reticular and hem-like pattern of pigmentation was observed on dermoscopy of clofazimine-induced pigmentation, peribuccal pigmentation of Brocq and periorbital pigmentation. Although the degree of agreement between Wood lamp and dermoscopic findings were found to be statistically significant in the different types of melasma and melasma with steroid-induced rosacea-like dermatitis, the agreement was higher for epidermal types and less for dermal and mixed types. We recommend further studies exploring dermoscopic, Wood lamp and histological findings in all facial melanoses.

\section{References}

1. Patel A, Kubba R, Kubba A. Clinicopathological correlation of acquired hyperpigmentary disorders. Indian J Dermatol Venereol Leprol. 2013;79(3):367-375. DOI: 10.4103/0378-6323.110798. PMID: 23619441.

2. Abdel-Naser M. The color of skin: gray diseases of the skin, nails, and mucosa. Clin Dermatol. 2019;37(5):507-515. DOI:10.1016/j. clindermatol.2019.07.011. PMID: 31896405.

3. Amatya B, Jha AK, Shrestha S. Frequency of different types of facial melanoses referring to the Department of Dermatology and Venereology, Nepal Medical College and Teaching Hospital in 2019, and assessment of their effect on health-related quality of life. BMC Dermatol.2020;20(1):1-7. DOI: 10.1186/s12895-02000100-3. PMID: 32746823; PMCID: PMC7398190.

4. Uitentuis S, Bekkenk M, van Geel N, de Rie M, Wolkerstorfer A. UV light set-ups for vitiligo photography, a comparative study on image quality and ease of use. J Eur Acad Dermatol. 2019;33(10):1971-1975. DOI:10.1111/jdv.15666. PMID: 31077457; PMCID: PMC6851740.

5. Lu QS, Chen X, Wang S, Xu SS, Wu T, Jiang G. Dermoscopy combined with Wood lamp, a diagnostic alternative for five pigmented lesions on the face: an observational study. Chin Med J. 2020; 133(22):2771-2772. DOI: 10.1097/CM9.0000000000001009. PMID: 32804732; PMCID: PMC7725530.

6. Tamler C, Fonseca R, Pereira F, et al. Classification of melasma by dermoscopy: comparative study with Wood's lamp. Surg Cosm Dermatol. 2009;1(3):115-119.

7. Dharni R, Madke B, Singh A. Correlation of clinicodermatoscopic and Wood's lamp findings in patients having melasma. Pigment Int. 2018;5(2):91-95. DOI: 10.4103/Pigmentinternational.Pigmentinternational_

8. Manjunath K, Kiran C, Sonakshi S, Agrawal R. Melasma: Through the eye of a dermoscope. Int J Res Dermatol. 2016;2(4):113-117. DOI: 10.18203/issn.2455-4529.IntJResDermatol20164071.

9. Nanjundaswamy B, Joseph J, Raghavendra K. A clinico dermoscopic study of melasma in a tertiary care center. Pigment Int. 2017;4(2):98-103. DOI: 10.4103/2349-5847.219678

10. Yalamanchili R, Shastry V, Betkerur J. Clinico-epidemiological Study and Quality of Life Assessment in Melasma. Indian J Dermatol. 2015;60(5):519. DOI: 10.4103/0019-5154.164415. PMID: 26538717; PMCID: PMC4601438.

11. Jakhar D, Kaur I. Dermoscopy of topical steroid damaged/ dependent face. Indian Dermatol Online J. 2018;9(4):286-287. DOI: 10.4103/idoj.idoj_301_17. PMID: 30050829; PMCID: PMC6042197. 
12. Elmas ÖF, Acar EM, Kilitçi A. Dermoscopic diagnosis of ashy dermatosis: A retrospective study. Indian Dermatol Online J. 2019;10(6):639-643. DOI: 10.4103/idoj.IDOJ_517_18. PMID: 31807441 ; PMCID: PMC6859771.

13. Vinay K, Bishnoi A, Parsad D, Saikia UN, Sendhil Kumaran M. Dermatoscopic evaluation and histopathological correlation of acquired dermal macular hyperpigmentation. Int J Dermatol. 2017;56(12):1395-1399. DOI: 10.1111/ijd.13782. PMID: 28971471.

14. Elmas ÖF, Kilitçi A. Dermoscopic Findings of Nevus of Ota. Balkan Med J. 2020;37(2):116-118. DOI: 10.4274/balkanmedj.galenos.2019.2019.11.46. PMID: 31852034; PMCID: PMC7094188.
15. El Kadiri S, Bay HB, Chaoui R, Douhi Z, Elloudi S, Mernissi FZ. A new dermoscopic finding in Ota nevus. Our Dermatol Online. 2020;11(e):e11.1-e11.2. DOI: 10.7241/ourd.2020e.11.

16. Chopra A, Mitra D, Agarwal R, Saraswat N, Talukdar K, Solanki A. Correlation of dermoscopic and histopathologic patterns in leprosy: A pilot study. Indian Dermatol Online J. 2019;10(6):663668. DOI: 10.4103/idoj.IDOJ_297_18. PMID: 31807445; PMCID: PMC6859759.

17. Jage M, Mahajan S. Clinical and dermoscopic evaluation of periorbital hyperpigmentation. Indian J Dermatopathol Diagn Dermatol. 2018;5(1):42-47. DOI: 10.4103/ijdpdd.ijdpdd_2_18. 